\title{
GENETIC AND PHENOTYPIC PARAMETERS OF BIRTH, WEANING AND YEARLING BODY WEIGHTS OF BARKI SHEEP RAISED IN THE NORTH WESTERN COAST OF EGYPT
}

\author{
Salwa I. EIWakil ${ }^{1}$, Manal EISayed ${ }^{2}$, A.M. Ahmed ${ }^{1}$, R.R. Sadek ${ }^{3}$ and A.A. \\ Nigm $^{3}$
}

1- Animal and Poultry Breeding Department, Desert Research Centre, EIMatareya, Cairo, Egypt, 2- Department of Animal Production, Faculty of Agriculture, Ein Shams University, Cairo, Egypt, 3- Department of Animal Production, Faculty of Agriculture, Cairo University, Giza, Egypt

\section{SUMMARY}

The present study investigated environmental factors affecting birth (BW), weaning (WW) and yearling body weights (YW) and estimated the heritabilities and genetic correlations of these traits in a Barki sheep flock maintained in the north western coast of Egypt. Body weight data of 1046 animals (542 females and 504 males) progenies of 163 sires and 557 dams obtained from 1963 to 2005 were used. Data were analyzed using a model composed of location, year of birth within location, sex of lamb and age of dam. Moreover, heritabilities as well as genetic and phenotypic correlations were estimated using multiple traits animal model.

Barki males had significantly heavier body weights than females at birth (3.64 kg vs $3.46 \mathrm{~kg}$ ), weaning (19.56 kg vs $18.44 \mathrm{~kg}$ ) and at 12-month of age (32.05 kg and $30.02 \mathrm{~kg}$ ). Year of birth within location showed highly significant effects on the studied body weights. Furthermore, age of dam revealed highly significant effect on birth weight, where older dams tend to produce heavier lambs than those of younger ones. These results clearly indicate that corrections for the studied environmental effects are necessary to increase accuracy of direct selection for $B W, W W$ and $Y W$.

Heritability for weaning weight was found to be higher (0.41) than BW (0.32) and $Y W$ (0.30). Therefore, selection based on WW would probably be more effective compared with $B W$ or $Y W$. Hence, heavier body weights at weaning are worth to be considered in the Barki sheep flock if the improvement of mutton production is the objective.

Keywords: Body weight, heritability, genetic correlations, Barki sheep, Egypt

\section{INTRODUCTION}

Improving the productive efficiency and particularly for mutton is the main objective towards the improvement of the local Barki sheep maintained in the north western coast (NWC) of Egypt. The breeding strategy to achieve such goal has been going on for so many years in the Barki sheep flock of the Desert Research Centre in the NWC. Barki is one of the main local sheep breeds of Egypt dominating in the 
NWC and known to be well adapted to the desert and harsh prevailing conditions as well as shortage of feed.

Genetic improvement for reproduction, lamb growth and fleece traits are usually considered as major goals for sheep production (Dickerson, 1978). Lamb growth traits are of significant importance for mutton production. Birth weight, weaning weight and yearling weight could probably indicate the growth features at three main stages in the animal life. These traits could also be taken as selection criteria to enhance the potentiality of mutton production in Barki sheep. Thus, estimating heritabilities and genetic correlations between these traits is of interest. However, these traits could be affected by various environmental factors that mask genetic differences when comparing animals (Kennedy, 1992). These factors must be corrected for to elucidate genetic differences between animals in order to increase the efficiency of selection procedures.

The present study aimed to investigate the environmental factors affecting birth, weaning and yearling body weights in Barki sheep and estimating the heritabilities and genetic correlations of these traits, since this information is prerequisite for designing any breeding programs.

\section{MATERIALS AND METHODS}

\section{Data}

The data used in the present study were collected from the Barki sheep flock raised at Ras ElHekma (RHRS), from 1963 to 1972, and Maryut Research Stations (MRS), from 1973 to 2005, belonging to the Desert Research Centre. RHRS is located 400 kilometers west of Alexandria while MRS is located 35 kilometers west of Alexandria. In 1972, sheep flock at RHRS moved to MRS.

\section{Flock Management}

Flock management in RHRS and MRS was almost the same where natural mating was practiced once a year (around July) and lambing started around December each year. The main difference between RHRS and MRS is natural grazing which was commonly used in the first one while indoor feeding with little grazing was practiced in the second station. At birth, lambs were ear-tagged, weighed and allowed to suckle their dams until weaning at 3-4 months of age. After weaning, animals were fed concentrate mixture of 0.5 to $1.0 \mathrm{~kg} /$ head / day according to their physiological status, in addition to ad-libitum of Berseem (Trifolium alexandrinum) hay. The concentrate mixture consisted of $50 \%$ cotton seed cake, $18 \%$ wheat bran, $15 \%$ yellow maize, $11 \%$ rice polish, $3 \%$ molasses, $2 \%$ limestone and $1 \%$ salt. Fresh water was made available for the flock once a day. Body weights were recorded just before morning feeding at biweekly intervals starting from birth till weaning and at monthly intervals afterwards until the animal removed from the flock.

\section{Data processing}

Body weight data obtained from the Barki sheep flock of the Desert Research Centre was utilized from 1963 to 2005 . Adjustments for individual body weights to different ages in the original data were carried out by intrapolation between the data of two successive ages; growth during the short intervals was assumed to be linear. Twin lambs were found to be very infrequent in the data, thus they were excluded 
from the original data. Consequently, a total of 1046 animals (542 females and 504 males) progenies of 163 sires and 557 dams were included in the analyses.

\section{Statistical model}

Data on birth weight (BW), weaning weight (WW) and yearling weight (YW) of lambs were analyzed using SAS (1998) to study the effect of location (L), year of birth within location (Y/L), sex of lamb (S) and age of dam at lambing (A). The statistical model was as follows:

Where :

$$
\mathbf{W}_{\mathrm{ijklm}}=\mathbf{u}+\mathbf{L}_{\mathrm{i}}+\mathbf{Y}_{\mathrm{i}(\mathrm{j})}+\mathbf{S}_{\mathrm{k}}+\mathbf{A}_{\mathbf{l}}+\mathbf{e}_{\mathrm{ijklm}}
$$

$\mathrm{W}_{\mathrm{ijklm}}=$ the record of $\mathrm{BW}, \mathrm{WW}$ or YW measured on $\mathrm{m}^{\text {th }}$ lamb born in $\mathrm{i}^{\text {th }}$ location at $\mathrm{j}^{\text {th }}$ year of birth within $\mathrm{i}^{\text {th }}$ location of $\mathrm{k}^{\text {th }}$ sex of lamb and $\mathrm{l}^{\text {th }}$ age of dam,

$\mathrm{u} \quad=$ the overall mean,

$\mathrm{L}_{\mathrm{i}}=$ the fixed effect of $\mathrm{i}^{\text {th }}$ location where $\mathrm{i}=1$ (RHRS) and 2(MRS),

$Y_{i(j)}=$ the fixed effect of $j^{\text {th }}$ year of birth within $i^{\text {th }}$ location (from year 1963 up to 1972 for location 1 and from year 1973 up to 2005 for location 2),

$\mathrm{S}_{\mathrm{k}}=$ the fixed effect of the $\mathrm{k}^{\text {th }}$ sex ( $\mathrm{k}=1$ for female and 2 for males), $\mathrm{A}_{1}=$ the fixed effect of $\mathrm{l}^{\text {th }}$ age of dam $(1=2,3,4$ and 5 years and more $)$, $\mathrm{e}_{\mathrm{ijklm}}=$ random error assumed to be $\operatorname{NID}\left(0, \sigma_{\mathrm{e}}^{2}\right)$.

The analysis of variance for the fixed model was performed using GLM procedure of SAS (1998). Moreover, genetic parameters for birth weight, weaning and yearling weights of 1046 records from 542 females and 504 males were estimated. Multiple trait animal model (MTDFREML) proposed by Boldman et al. (1993) was used to estimate the heritability, genetic and phenotypic parameters for BW, WW and YW. The same fixed effects of model (1) were included in this analysis beside the animal, sire and dam as random effects. The following linear model was used:

$$
\mathbf{Y}=\mathbf{X} \boldsymbol{\beta}+\mathbf{Z}_{\mathbf{a}} \mathbf{a}+\mathbf{e}
$$

Where:

$\mathrm{Y}=$ is $\mathrm{N}$ vector of observations of $\mathrm{BW}, \mathrm{WW}$ or $\mathrm{YW}$,

$\mathrm{X}=$ is the incidence matrix for fixed effects mentioned previously in model (1),

$\beta=$ is the vector including the overall mean and the same fixed effects as those stated in model (1),

$\mathrm{Z}_{\mathrm{a}}=$ is the incidence matrix for random effects,

$\mathrm{a}=$ is the vector of direct genetic effect of the animal; and

$\mathrm{e}=$ is a vector of random residuals normally and independently distributed with zero mean and variance $\sigma_{\mathrm{e}}^{2} \mathrm{I}$.

The variance-covariance structure for the model is as follows:

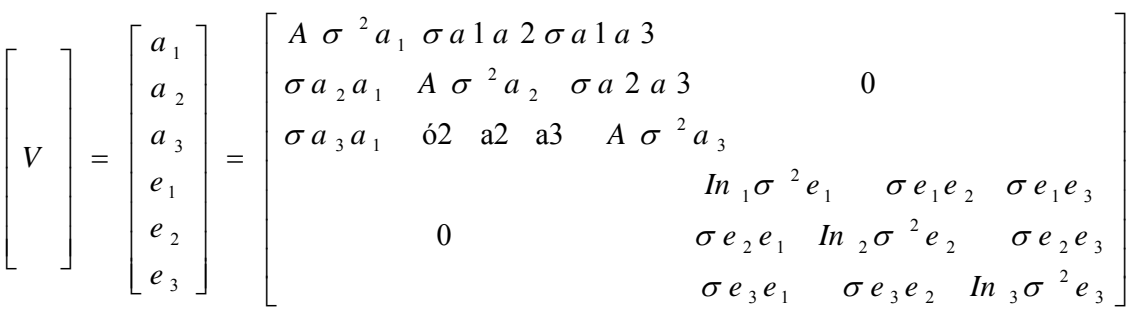


where:

A is the numerator relationship matrix,

$\sigma^{2} a_{1}, \sigma^{2} a_{2}$ and $\sigma^{2} a_{3}$ Are the direct genetic variance(s) for

$\mathrm{BW}, \mathrm{WW}$ and $\mathrm{YW}$,

oala2, oala3and oa $2 a 3$ Are the direct genetic covariance(s) between

traits,

$\sigma^{2} \mathrm{e}_{1}, \sigma^{2} \mathrm{e}_{2}$ and $\sigma^{2} \mathrm{e}_{3} \quad$ Are the error variance(s) for studied traits,

oele2, oele3and $\sigma e 2 e 3$ Are the error covariance(s) between traits.

\section{RESULTS AND DISCUSSION}

The present study estimated the overall average body weight for Barki sheep as $3.46 \mathrm{~kg}$ at birth, $14.46 \mathrm{~kg}$ at weaning and $23.82 \mathrm{~kg}$ at 12-month of age (Table 1). Maryut research station showed slightly heavier lambs at birth while had significantly heavier animals at weaning and yearling stages compared with Ras ElHekma research station. Tables (1 and 2) also indicated that males are often significantly heavier than females at birth, weaning and yearling stages. Moreover, age of dam showed highly significant effect on birth weight (BW) whereas no significant effects existed on weaning (WW) and yearling weights (YW).

In the same flock, Mokhtar et al. (1991) estimated average birth weights for males $(3.69 \mathrm{~kg})$ and females $(3.49 \mathrm{~kg})$, average weaning weight for males $(18.61 \mathrm{~kg})$ and females $(17.37 \mathrm{~kg})$ as well as average yearling weight for males $(33.18 \mathrm{~kg})$ and females (30.65 kg). Later, Ahmed et al. (1992) showed estimates of $2.92 \mathrm{~kg}, 14.1$ and $28.7 \mathrm{~kg}$ for the averages of body weights at birth, weaning and yearling, respectively. Moreover, Bedier et al. (1995) found that average birth weight, weaning weight and yearling weight for Barki sheep in the same flock were $3.45 \mathrm{~kg}, 19.9 \mathrm{~kg}$ and $32.7 \mathrm{~kg}$, respectively.

Table 1. LSMEAN \pm SE for birth (BW), weaning (WW) and yearling (YW) body weights (in kg) in both sexes in Barki sheep

\begin{tabular}{|c|c|c|c|c|}
\hline Factors & & Birth weight & $\begin{array}{l}\text { Weaning } \\
\text { weight }\end{array}$ & Yearling weight \\
\hline \multicolumn{5}{|c|}{ Location } \\
\hline & RHRS & $3.42 \pm 0.04$ & $12.30 \pm 0.52$ & $21.32 \pm 0.82$ \\
\hline & MRS & $3.48 \pm 0.03$ & $16.61 \pm 0.37$ & $26.31 \pm 0.59$ \\
\hline \multicolumn{5}{|l|}{ Sex } \\
\hline & Male & $3.55 \pm 0.03$ & $15.03 \pm 0.40$ & $24.98 \pm 0.63$ \\
\hline & Female & $3.34 \pm 0.03$ & $13.88 \pm 0.38$ & $22.64 \pm 0.61$ \\
\hline \multicolumn{5}{|c|}{ Age of dam } \\
\hline & 2 & $3.22 \pm 0.04^{\mathrm{a}}$ & $14.17 \pm 0.56^{\mathrm{a}}$ & $23.70 \pm 0.89^{\mathrm{a}}$ \\
\hline & 3 & $3.49 \pm 0.04^{b}$ & $15.00 \pm 0.53^{\mathrm{a}}$ & $24.84 \pm 0.84^{\mathrm{a}}$ \\
\hline & 4 & $3.49 \pm 0.05^{\mathrm{c}}$ & $13.93 \pm 0.61^{\mathrm{a}}$ & $22.31 \pm 0.96^{\mathrm{a}}$ \\
\hline & 5 & $3.59 \pm 0.03^{d}$ & $14.73 \pm 0.46^{\mathrm{a}}$ & $24.41 \pm 0.73^{a}$ \\
\hline
\end{tabular}


Table 2. Analysis of variance for birth (BW), weaning (WW) and yearling (YW) body weights in Barki sheep

\begin{tabular}{lcccc}
\hline \multirow{2}{*}{ Source } & DF & \multicolumn{3}{c}{ Mean Squares } \\
\cline { 3 - 5 } & & Birth weight & $\begin{array}{c}\text { Weaning } \\
\text { weight }\end{array}$ & $\begin{array}{c}\text { Yearling } \\
\text { weight }\end{array}$ \\
\hline Location & 1 & 0.58 & $2881.28^{* *}$ & $3863.85 * *$ \\
Year/ location & 25 & $1.73^{* *}$ & $728.39 * *$ & $1789.75^{* *}$ \\
Sex & 1 & $13.31 * *$ & $420.37 * *$ & $1737.75 * *$ \\
Age of dam & 3 & $6.22 * *$ & 55.10 & 267.79 \\
Residual & 1261 & 0.35 & 63.29 & 158.23 \\
Total & 1291 & & & 0.21 \\
R-square & & 0.16 & 0.23 & 48.34 \\
c.v. & & 16.91 & 48.78 & \\
\hline
\end{tabular}

** Significant at $\mathrm{P}<0.01$

The present estimates appeared to be comparable with the corresponding estimates of some local sheep breeds, the Ossimi where average birth weight was found to be ranged from 3.32 to $3.48 \mathrm{~kg}$ (Aboul-Naga and Mansour,1991; Mousa et al.,1994) as well as weaning and yearling weights averaging $12.3 \mathrm{~kg}$ and $34.0 \mathrm{~kg}$, respectively according to Aboul-Naga and Mansour (1991). On the other hand, for Awassi sheep, Mousa et al. (1994) estimated average birth weight and weaning weight as $3.32 \mathrm{~kg}$ and $12.2 \mathrm{~kg}$, respectively.

Tables ( 1 and 2 ) indicated that while Barki males had significantly heavier body weights than Barki females, differences between sexes increased as age advanced from birth to weaning up till yearling. The coefficient of variation appeared to be much higher at weaning and yearling compared with that at birth as many factors seemed to be involved in the variations of body weights at later stages compared with those involved at lambing.

In Barki sheep, some local breeds and other coarse wool breeds, many authors indicated the significance of the sex of lamb effect where males were found to be generally heavier than females in Barki sheep (Mokhtar et al., 1991; Ahmed et al., 1992; Bedier et al., 1995), Rahmani (Aziz and Abdelsalam,1993; Abdel-Aziz,1994), Awassi (Ghoneim et al., 1982) and Yemeni Dhamari sheep (Al-bar et al., 2002).

As expected, location and year of birth within locations generally showed highly significant effects on body weights at birth, weaning and yearling stages. Fluctuations in some environmental factors prevailed; in particularly quality and quantity of the available feed stuff could be an explanation. Moreover, the effect of locations could be looked at a combination of some genetic and environmental factors affecting animal performance. Year of birth showed significant effect on body weights in Barki (Ahmed et al., 1992; Bedier et al., 1995), Rahmani (Aziz and Abdelsalam,1993), Awassi (Kassab,1975) and Yemeni Dhamari sheep (Al-bar et al., 2002). Figures (1 and 2) indicated that while body weights generally tend to increase, more fluctuations in WW and YW compared with BW appeared for so many years with no clear trends despite the breeding plan implemented in this flock. Probably the management of this flock as well as the effectiveness of the breeding plan has to be considered in order to proceed with the improvement of mutton production in this flock. 


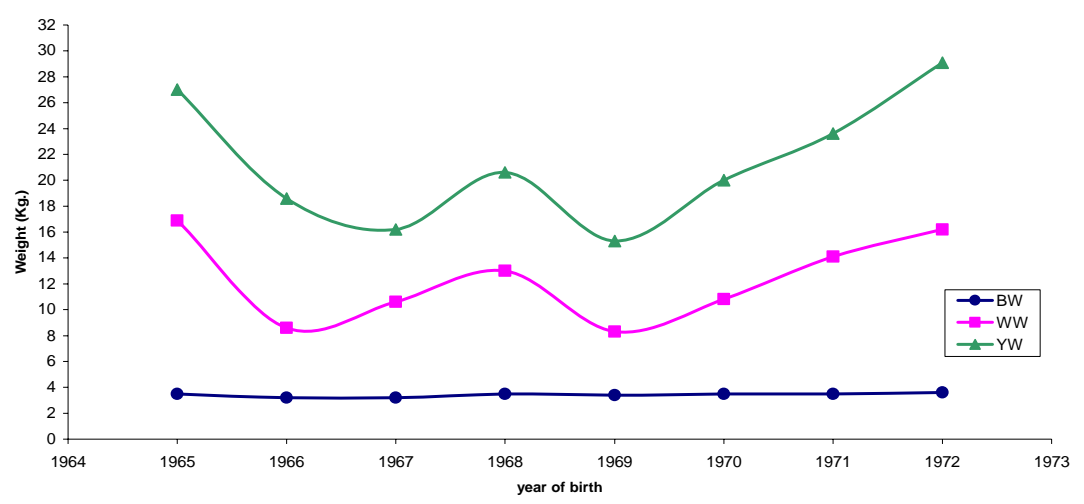

Fig.(1). The relationships between year of birth and body weights at birth (BW),weaning (WW) and yearling (YW) at Ras ElHekma research station.

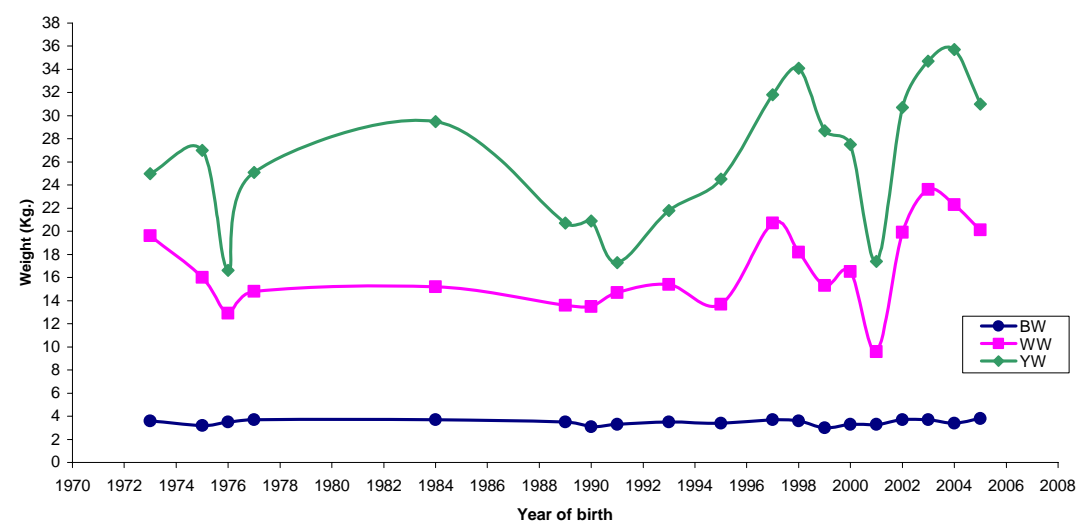

Fig. (2). The relationships between year of birth and body weights at birth (BW), weaning (WW) and yearling (YW) at Maryut research station.

Age of dam showed a highly significant effect on birth weight but not on weaning and yearling weights, where older dams tend to produce heavier lambs than those of younger dams in Barki sheep (Tables 1 and 2). This result might indicate that birth weight of the lamb would depend almost entirely on the performance of his dam. As the lamb gets older he would be capable to express his own performance. Similar findings were reported for Barki sheep (Mokhtar et al., 1991; Ahmed et al., 1992), Rahmani sheep (Abdel-Aziz,1994; Aziz and Abdelsalam,1993), Awassi sheep (Ghoneim et al., 1982) and Yemeni Dhamari sheep (Al-bar et al., 2002). 
The aforementioned results clearly indicate the significance of some environmental factors such as location, year of birth within location, sex and age of dam on the studied body weights. Thus, corrections for these environmental effects are necessary to increase accuracy of direct selection for birth, weaning and yearling weights in Barki sheep. Improving and controlling the environmental factors could help genetic factors to show their effects on animal body weights. Thus, improvement of growth performance in Barki sheep could be attained if reasonable levels of flock management as well as selection pressure are maintained.

Table (3) shows that weaning weight has higher heritability $(0.41)$ than birth $(0.32)$ and yearling weights $(0.30)$. Moreover, weaning weight was found to have higher genetic correlations with yearling weight $(0.92)$ than that of birth weight (0.74). The present heritability estimates are comparable with other estimates obtained elsewhere. The heritabilities of birth weight was found to be ranged between 0.25 and 0.81in Barki lambs (Guirgis et al., 1982; Abdel-Aziz, 2000) and 0.66 in Rahmani lambs (Abdel-Aziz, 2000). The corresponding estimates for weaning weight were found to be ranged between 0.21 to 0.27 in Barki sheep (Guirgis et al.,1982; Abdel-Aziz, 2000), between 0.26 to 0.28 in Rahmani (Abdel-Aziz,2000; Shaat et al., 2004), 0.24 in Ossimi (Shaat et al., 2004). Moreover, Guirgis et al., (1982) estimated the heritability of yearling weight as 0.28 in Barki sheep. On the other hand, AbdelAziz (2000) reported the genetic correlations between birth weight and weaning weight as 0.36 while the phenotypic correlation estimate was found to be 0.27 in Barki lambs. The corresponding values for Rahmani sheep were 0.72 and 0.38 for the genetic and phenotypic correlations, respectively.

Table 3. Heritabilites (on diagonal) an genetic correlations (below diagonal) for birth (BW), weaning (WW) and yearling (YW) body weights in Barki sheep

\begin{tabular}{cccc}
\hline Trait & BW & WW & YW \\
\hline BW & 0.32 & & \\
WW & 0.74 & 0.41 & \\
YW & 0.74 & 0.92 & 0.30 \\
\hline
\end{tabular}

Selection based on weaning weight might be more effective for its higher heritability compared with birth and yearling weights. It is fortunate to rely on weaning weight in selection program since heavier body weights at weaning are worth to be considered in the flock if the improvement of mutton production is the objective. Practically, sheep breeders usually evaluate their lambs after weaning either by selling them or keeping them for breeding purposes. It would also be of advantage to find out that heavier weaning weight would be associated with more increase in yearling weight than that of birth weight. The increase in yearling weight would meet the breeder and consumer preferability while reducing birth weight would avoid dyscostia.

\section{ACKNOWLEDGEMENT}

The authors would like to thank Prof. Hasanein ElGabbas, Professor of Animal Breeding, Desert Research Centre for assisting in reviewing the manuscript. Thanks 
are also extended to the animal breeding unit of the Desert Research Centre for providing the data.

\section{REFERENCES}

Abdel-Aziz, M., 1994. Evaluation of some environmental factors affecting weaning weight of Rahmany and Barki lambs. Alexandria Journal of Agricultural Research, 39(2): 149-166.

Abdel Aziz, M., 2000. Heritability, genetic and phenotypic correlations of preweaning growth traits of Rahmany and Barki lambs. Alexandria Journal of Agricultural Research, 45(1): 13-21.

Aboul-Naga, A. M. and H. Mansour, 1991. Crossbreeding system utilizing desert and valley native sheep breeds. Proceedings of the Second International Desert Development Conference, held on 25-31 January 1987 in Cairo, Egypt. Part 1: 521-530.

Ahmed, A. M., E.S.E. Galal, and A.A. Younis, 1992. Estimates of productive and reproductive performances of a commercial flock of Barki sheep. Egyptian Journal of Animal Production, 29(1): 109-122.

Al-bar, A., A. Al-Nokhaif, A. Al-Aghberi, A. Mulsi, 2002. Estimation of non-genetic parameters for some growth traits in Dhamari hair sheep. University of Aden Journal of Natural and Applied Sciences, 6(2): 325-332.

Aziz, M.A. and M.M. Abdelsalam, 1993. Additive and multiplicative correction factors for lamb birth weight in some Egyptian sheep breeds. Alexandria Journal of Agricultural Research, 38(3): 139-151.

Bedier, N.Z., A.A. Younis, M.M. Mokhtar, 1995. Performance of Barki lambs in a stud ram flock. Desert Institute Bulletin, Egypt, 46(1): 1-7.

Boldman, K.G., L.A. Kriese, L.D. Van Vleck and S.D. Kachman, 1993. A manual for use of MTDFREML. A set of programs to obtain estimates of variances and covariances (DRAFT). U.S. Department of Agriculture, Agricultural Research Service, p. 114.

Dickerson, G. E., 1978. Animal size and efficiency. Anim. Prod., 27: 367.

Ghoneim, K.E., R.R. Shrode, R.K. Abdallah, 1982. Statistical analysis of birth weight in Awassi sheep in northern Iraq. Proceedings of the Sixth International Conference on Animal and Poultry Production, held at University of Zagazig, Zagazig, Egypt, 21-23 September, 1982, Vol. 2:488-496.

Guirgis, R.A., E.A. Afifi, E.S.E. Galal, 1982. Estimates of genetic and phenotypic parameters of some weight and fleece traits in a coarse-wool breed of sheep. Journal of Agricultural Science, UK, 99(2): 277-285.

Kassab, S.A., 1975. Some environmental factors affecting birth weight in Awassi sheep. Agriculture Pakistan, 26(2): 207-212.

Kennedy, B.W., 1992. Genetic of milk and type. Ontario Agric. College Guelph, Canada. Collection at the National Agricultural library. Doc no 27, p 1-5. RV.D. Van Vleck, Cornell U., Ithaca, NY.

Mokhtar, M.M., H. Mansour, A.A. Younis, H. El-Gabbas, 1991. Growth and mature size in fat-tailed sheep. Egyptian Journal of Animal Production, 28(1): 39-46.

Mousa, M.T., M.M. Shetaewi, E. Shehata, 1994. Ovulation rate and reproductive performance of Ossimi, Awassi and Chios sheep and their crosses. Egyptian Journal of Animal Production, 31(1): 137-147. 
SAS, 1998. Statistical analysis system. SAS user's guide: Statistics. SAS institute inc. Editors, Cary, NC.

Shaat, I., S. Galal, H. Mansour, 2004. Genetic trends for lamb weights in flocks of Egyptian Rahmani and Ossimi sheep. Small Ruminant Research, 51(1): 23-28. 
المعالم الوراثية والمظهرية لأوزان الجسم عند الميلاد والفطام وعمر سنة فى الأغنام

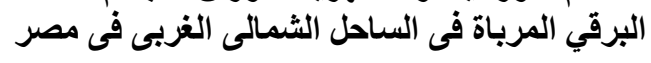

سلوى ابراهيم الوكيل،، منال السيد²، على مصطفى أحمد1، ربيع صادق3، على عطية نجم3

1- قسم تربية الحيوان والدواجن-مركز بحوث الصحراء، 2ـ قسم الانتاج الحيوانس_كلية الزراعةـ جامعة عين

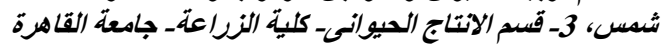

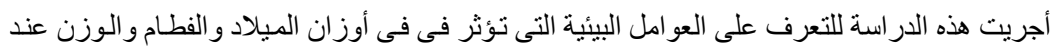

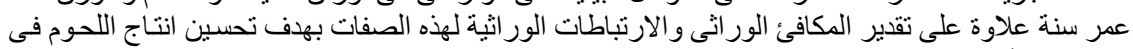

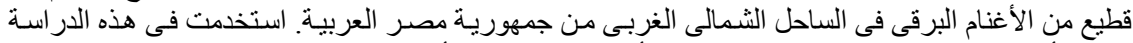

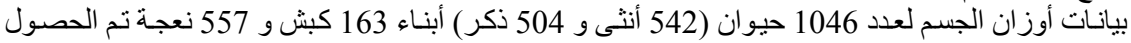

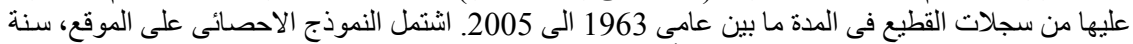

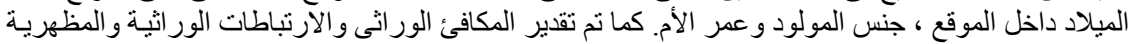

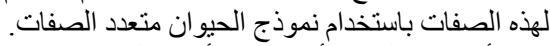

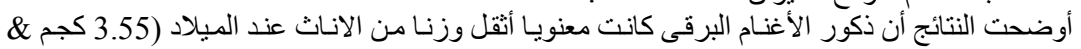

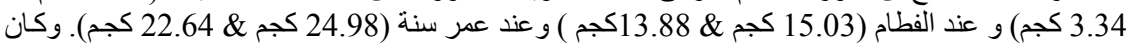

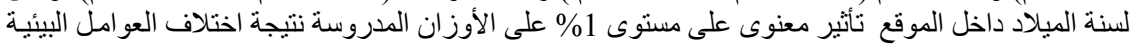

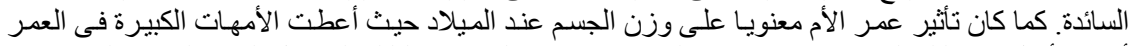

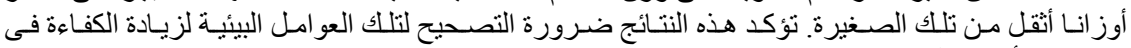

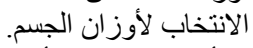

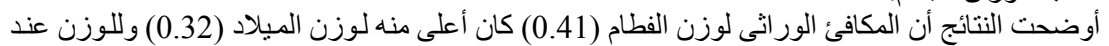

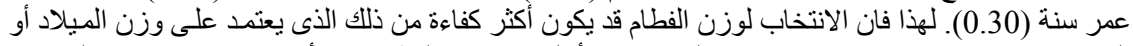

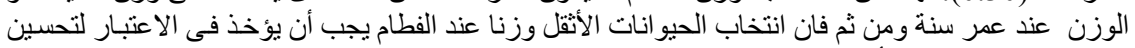

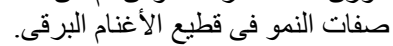

